\title{
Photoactive Layer of DSSCS Based on Natural Dyes: A Study of Experiment and Theory
}

\author{
Yuanzuo Li, ${ }^{1}$ Huixing Li, ${ }^{2}$ Peng Song, ${ }^{3}$ and Chaofan Sun ${ }^{1}$ \\ ${ }^{1}$ College of Science, Northeast Forestry University, Harbin, Heilongjiang 150040, China \\ ${ }^{2}$ School of Physics and Optoelectronic Technology, Dalian University of Technology, Dalian 116024, China \\ ${ }^{3}$ Department of Physics, Liaoning University, Shenyang, Liaoning 110036, China
}

Correspondence should be addressed to Yuanzuo Li; yuanzuo.li@gmail.com

Received 10 August 2015; Accepted 12 October 2015

Academic Editor: Tran V. Cuong

Copyright (C) 2015 Yuanzuo Li et al. This is an open access article distributed under the Creative Commons Attribution License, which permits unrestricted use, distribution, and reproduction in any medium, provided the original work is properly cited.

\begin{abstract}
Three natural dyes (Forsythia suspensa, Herba Violae, and Corn leaf) have been investigated as potential sensitizers for dyesensitized solar cells. UV-vis absorption spectra reveal that three natural dyes mainly contain the compound of pheophytin a. Among three DSSCs, the highest photo electronic conversion efficiency $\eta$ is $0.96 \%$ with open circuit voltage $\left(V_{\text {OC }}\right)$ of $0.66 \mathrm{~V}$, short circuit current density $\left(I_{\mathrm{SC}}\right)$ of $1.97 \mathrm{~mA} \mathrm{~cm}^{-2}$, and fill factor (ff) of 0.74 . Theoretical time-dependent density functional theory and charge difference density are used to explore the nature of excited states. Results demonstrate that the first state is an intramolecular charge transfer (ICT) state, and electron injection could occur owing to the thermodynamically driving force.
\end{abstract}

\section{Introduction}

Since the initial report on dye-sensitized solar cells (DSSCs) by Hagfeldt and Graetzel [1], much effort has been devoted toward designing and synthesizing metal-free photosensitizers to improve sunlight harvesting efficiency and yield efficient charge separation [2-5]. Most of the efficient DSSCs are sensitized with the dyes having ruthenium based complexes that have been shown to operate with power conversion around $10 \%$ using nanoporous $\mathrm{TiO}_{2}$ electrodes [6]. However, due to the high cost of ruthenium complexes and the long term unavailability of these noble metals [7], there is a need to search for alternative photosensitizers for the use in $\mathrm{TiO}_{2}$ based photovoltaic devices.

Recently, several studies have focused on the natural dyes as DSSCs sensitizers [8-15] because the natural dyes could be extracted from flowers, vegetables, wood, seed, fruits, and so forth, by using minimal chemical procedures. Several natural pigments such as anthocyanin [10-12], chlorophyll [13], tannin [14], and carotene [15] have been used as sensitizer in DSSCS, and the highest photoelectronic conversion efficiency $\eta$ based on natural dyes is around $2 \%[10,11]$. In this study, we extract three dyes from natural plants of Forsythia syspensa,
Herba Violae, and Corn leaf to use as DSSCS and achieve the highest efficiency $\eta=0.96 \%$ with a good fill factor of 0.74 under AM 1.5 using a density of power $100 \mathrm{~mW} / \mathrm{cm}^{2}$.

\section{Methods}

Forsythia suspensa (Fs), Herba Violae (Hv), and Corn leaf (Cl) were collected fresh and kept in a vacuum furnace by controlling temperature at $70^{\circ} \mathrm{C}$ to remove the moisture. The dried samples were crushed in a mortar to make them into powder, and then powdered samples were mixed into ethanol, and the concentration of three samples is $1 \mathrm{~g} / \mathrm{mL}$. After extraction for about a week under the opaque condition, further purification of the extracts was avoided in order to achieve efficient sensitization using simple extraction procedures. The structure of DSSCs is mainly composed of electrode, dyes, and electrolyte solution. The elaborated preparation procedure is listed as follows: (a) the $\mathrm{TiO}_{2}$ electrode was prepared; add $10 \mathrm{~mL}$ isopropyl titanate to water, and keep hydrolysis for $3 \mathrm{~h}$; then add $\mathrm{HNO}_{3}$ and $\mathrm{HAC}$ to the solution, under $80^{\circ} \mathrm{C}$; the mixed solution was stirred until it became transparent clear blue; later, at $200^{\circ} \mathrm{C}$ hydrothermal reaction was carried on for $12 \mathrm{~h}$. After cooling and spin steaming, 
centrifugal, terpineol ethyl, and cellulose were added to the ball grinder; the paste was prepared completely by ball mill, rotary steam, and three-roll mill. (b) The application of screen printing technology was used, which printed the $\mathrm{TiO}_{2}$ paste to the clean surface of conductive glass, and the active area of cell was $0.16 \mathrm{~cm}^{2}$; after ethanol bath and drying, the anode electrodes were sintered, and then the anode electrodes were treated in $\mathrm{TiCl}_{4}$ solution. In the next process, the anode electrodes were sintered as well, and after the processing, the anode immediately was removed after the natural cooling to $80^{\circ} \mathrm{C}$, and the anode electrodes were soaked in the natural dye without light for $24 \mathrm{~h}$. (c) The anode electrode and the platinum plating counter electrode were assembled into the cell, in the middle of the two electrodes, and the electrolyte solution was added $(0.5 \mathrm{~mol} / \mathrm{L} \mathrm{LiI,} 0.05 \mathrm{~mol} / \mathrm{L} \mathrm{I} 2 \mathrm{TBP}$, and GUSCN were included). UV-vis spectra were measured with TU-1900 spectrometer (Beijing, China), and the FT-IR spectra were measured with FT-IR 360 spectrometer (Nicolet, Madison, WI, USA). Solar energy conversion efficiency measurements were done with a solar simulation instrument (Pecell-15, Japan), and light intensity was adjusted via a reference standard $\mathrm{Si}$-solar solar cell at 1 sun light intensity of $100 \mathrm{~mW} \mathrm{~cm}^{-2}$. Theoretically, the ground state optimization and absorption simulation were done with DFT/B3LYP [1619] and TD-DFT/CAM-B3LYP [20, 21] using same basis set 6-31G(d). For comparison, M062x function was also used. All quantum chemical calculations were done with Gaussian 09 [22]. Quantum chemical calculations [23-27] and threedimensional (3D) real-space analyses $[25,26]$ were used to study the relationship between structures and the optical properties, which has been used to explain charge transfer and excited states properties of organic system.

\section{Results and Discussion}

UV-vis absorption spectra of Forsythia suspensa (Fs), Herba Violae $(\mathrm{Hv})$, and Corn leaf $(\mathrm{Cl})$ in ethanol were shown in Figure 1(a), and for comparison, simulated absorption spectrum was shown in Figure 1(b), and the calculated data were listed in Table 1. It is found that the absorption spectra of three dyes cover the two absorption bands from $400 \mathrm{~nm}$ to $700 \mathrm{~nm}$, and they display a strongest absorption band $(666-669 \mathrm{~nm})$ that corresponds to the red absorption band $(666 \mathrm{~nm})$ of pheophytin a $[28,29]$. The calculation reproduces the two absorption spectra of dyes (see Figure 1(b)), and the first absorption in ethanol is found to be $595.51 \mathrm{~nm}(f=0.17)$ by using TD-CAMB3LYP/6-31G(d)//B3LYP/6-31G(d), which makes a red shift of $50 \mathrm{~nm}$ compared with the first absorption peak with TD-M062x/6-31G(d)//B3LYP/6-31G(d) $\left(\lambda_{\max }=\right.$ $545 \mathrm{~nm})$.

The transition energy and oscillator strength were listed in Table 1. As shown in Table 1, it is found that the excited state is composed of electron transition from HOMO to LUMO with the weight of 0.62279 . It is very important for DSSCS to perform well with energy match; that is, the HOMO energy level should be laid below the redox couple, and LUMO energy level should be higher than that of $\mathrm{TiO}_{2}$ semiconductor. Therefore, the energy level match is necessary
TABLE 1: Calculated transition energies and oscillator strengths TE (OS) and CI coefficients for the six excited states.

\begin{tabular}{lccr}
\hline States & TE $(O S)$ & CI coefficients & Cal. $^{[\mathrm{a}]}$ \\
\hline 1 & $595.51(0.1700)$ & $(0.62279) \mathrm{H} \rightarrow \mathrm{L}$ & $545 \mathrm{~nm}$ \\
2 & $508.40(0.0332)$ & $(0.58102) \mathrm{H}-1 \rightarrow \mathrm{L}$ & \\
3 & $357.08(0.8698)$ & $(0.54625) \mathrm{H} \rightarrow \mathrm{L}+1$ & \\
4 & $352.01(0.9375)$ & $(0.53325) \mathrm{H}-1 \rightarrow \mathrm{L}$ & \\
5 & $335.49(0.2486)$ & $(0.61823) \mathrm{H}-2 \rightarrow \mathrm{L}$ & \\
6 & $316.61(0.0088)$ & $(0.50112) \mathrm{H}-5 \rightarrow \mathrm{L}$ & \\
\hline
\end{tabular}

${ }^{[a]}$ Data from TD-M062x/6-31G(d)//B3LYP/6-31G(d).

TABLE 2: Current-voltage characteristics of Forsythia suspensa (Fs), Herba Violae (Hv), and Corn leaf (Cl).

\begin{tabular}{lcccc}
\hline & $V_{\mathrm{OC}}(\mathrm{V})$ & $J_{\mathrm{SC}}(\mathrm{mA} / \mathrm{cm})$ & FF & Eff./\% \\
\hline Fs & 0.64 & 2.01 & 0.70 & 0.90 \\
$\mathrm{Hv}$ & 0.66 & 1.97 & 0.74 & 0.96 \\
$\mathrm{Cl}$ & 0.61 & 0.99 & 0.78 & 0.47 \\
\hline
\end{tabular}

for the optical electronic transfer and electron recovery in the system of solar cells. Comparison results show that the HOMO energy level is found to be $-5.21 \mathrm{eV}$, which is lower than that of HOMO of the redox couple $\mathrm{I}^{-} / \mathrm{I}^{3-}(-4.8 \mathrm{eV}$ $[28,29])$, which means that excited dye can obtain electron from the redox couple to recovery; and LUMO energy level is $-2.736 \mathrm{eV}$, which is above the conduction band of $\mathrm{TiO}_{2}$. The energy gap is $2.474 \mathrm{eV}$, and exciton binding energy can be obtained from the difference values between excitation energy and energy gap, which are $0.392 \mathrm{eV}$ and $0.199 \mathrm{eV}$ through the two functional evaluations of CamB3LYP and M062x, respectively.

Fourier transform infrared spectrum of three dyes in the range of $400-4000 \mathrm{~cm}^{-1}$ was measured experimentally, as shown in Figure 2(a). For comparison, a simulated spectrum in ethanol was also calculated theoretically (see Figure 2(b)). Figure 2(a) shows that the three dyes have similar shape and peak site of IR, and strong spectra of IR are found to be 3000$4000 \mathrm{~cm}^{-1}$ and $1000-2000 \mathrm{~cm}^{-1}$, that is, $1107.15,1398.74$, $1634.78,2359.23,2924.52$, and $3420.00 \mathrm{~cm}^{-1}$, respectively. Figure 2(b) shows that there is a peak site of $3520 \mathrm{~cm}^{-1}$, and it is a vibration of $\mathrm{N}-\mathrm{H}$, as supported by the vibration analysis in Figure 3. From 3000 to $3200 \mathrm{~cm}^{-1}$ region, the vibration of $3072 \mathrm{~cm}^{-1}$ comes from the stretching vibration of $\mathrm{C}-\mathrm{H}$ on polyene hydrocarbon (see Figure 3 ). The stretching vibrations of $\mathrm{C}=\mathrm{O}$ on the thiophene units and carboxyl group are $1752 \mathrm{~cm}^{-1}$ and $1795 \mathrm{~cm}^{-1}$, respectively. The sharp and strong absorption peaks for $\mathrm{C}=\mathrm{C}$ stretching mode and the out of plane of C-H bending mode were $1660 \mathrm{~cm}^{-1}$ and $952 \mathrm{~cm}^{-1}$, respectively.

Current-voltage curves for Fs (black line), Hv (red line), and $\mathrm{Cl}$ (blue line) were shown in Figure 4, respectively. Table 2 shows $I-V$ (current-voltage) characteristics of the DSSCs sensitized with three dyes, which are composed of short circuit current density $\left(I_{\mathrm{SC}}\right)$, open circuit voltage $\left(V_{\mathrm{OC}}\right)$, fill factor (ff), and energy conversion efficiency $(\eta)$. The DSSCs sensitized with Herba Violae dye showed conversion 


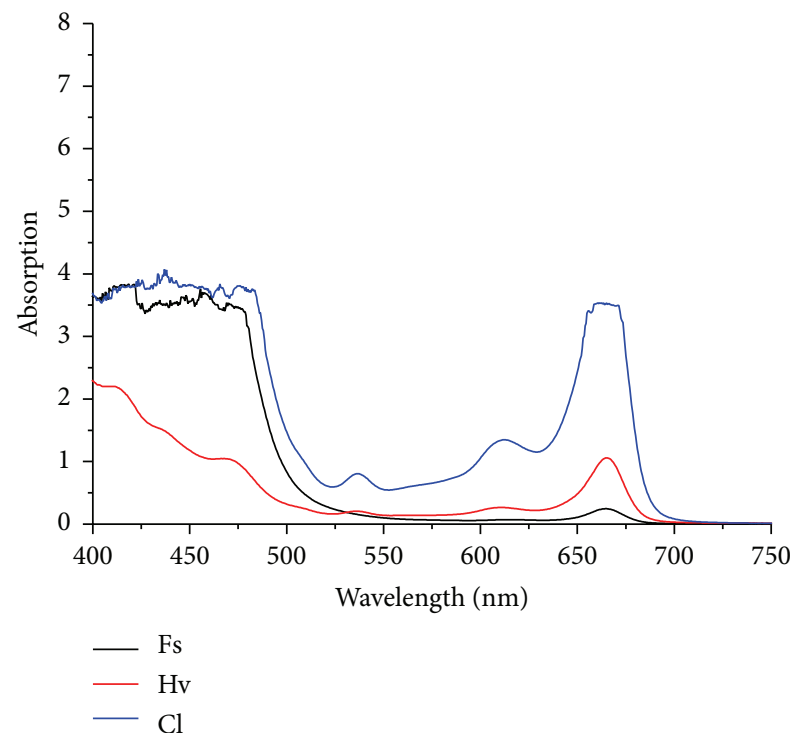

(a)

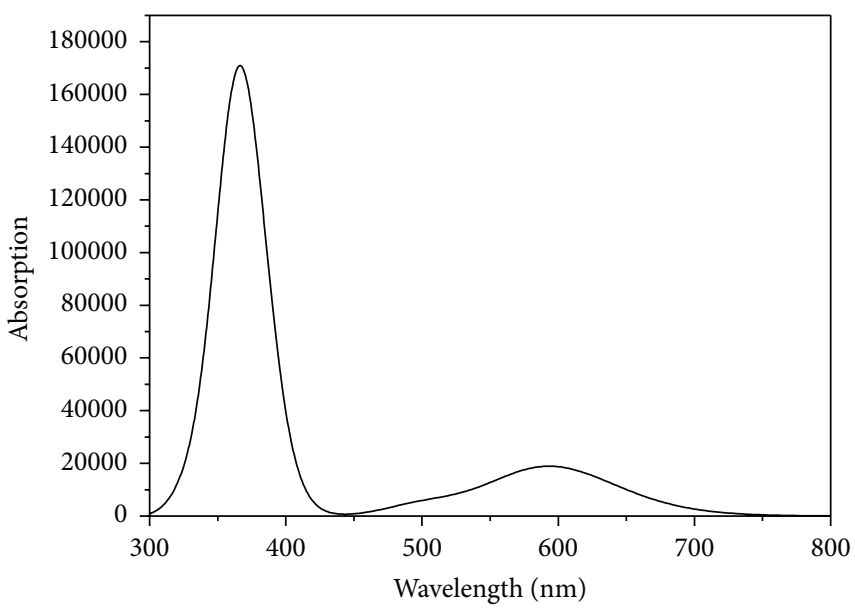

(b)

FIGURE 1: Absorption spectra of experiment (a) and simulation (b).

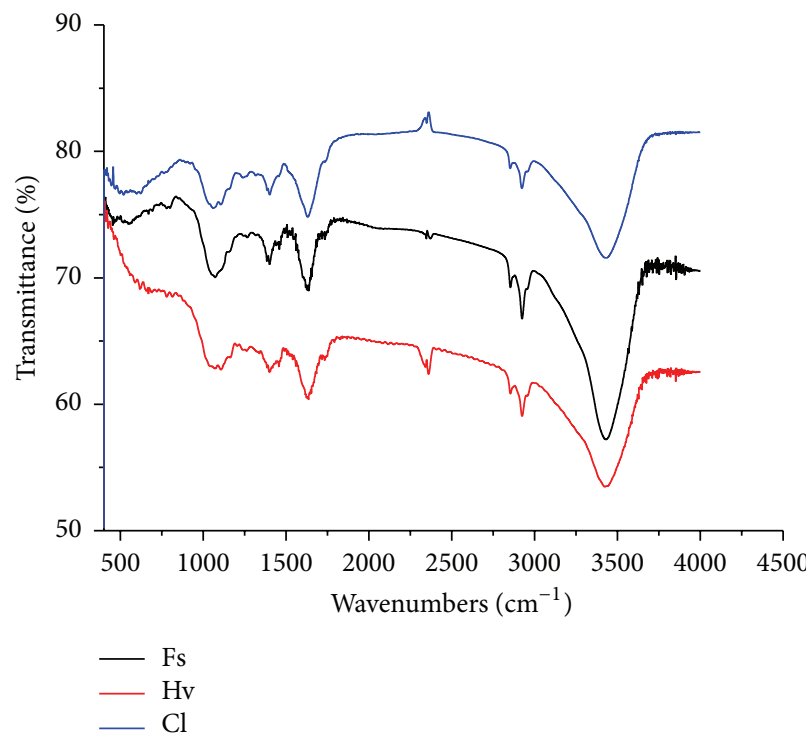

(a)

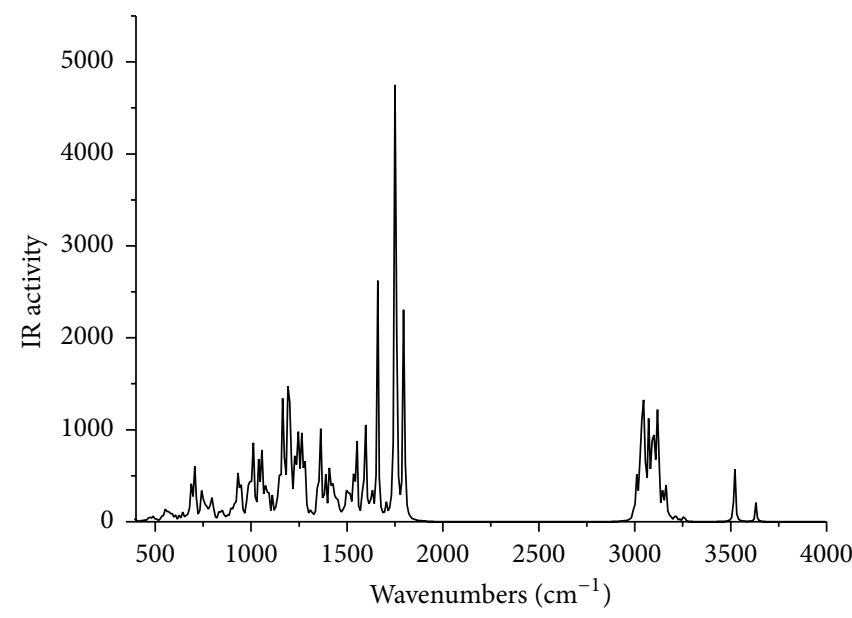

(b)

FIgURE 2: Experimental and theoretical IR spectra (a) and (b).

efficiency $(\eta)$ of $0.96 \%$, with open circuit voltage $\left(V_{\text {OC }}\right)$ of $0.66 \mathrm{~V}$, short circuit current density $\left(I_{\mathrm{SC}}\right)$ of $1.97 \mathrm{~mA} \mathrm{~cm}^{-2}$, and fill factor (ff) of 0.74 . The DSSCs sensitized with Fs showed conversion efficiency $(\eta)$ of $0.90 \%$, and the open circuit voltage of Fs is smaller than that of $\mathrm{Hv}$, but short circuit current density of Fs is larger than that of Hv. For three solar cells, the values of $V_{\mathrm{OC}}$ and $I_{\mathrm{SC}}$ for $\mathrm{Cl}$ are both smaller than the two other cells, and its conversion efficiency $(\eta)$ is 0.47 .

To better study the excited states properties of the dye, the $3 \mathrm{D}$ real-space analysis is employed, which successfully explained the excited states properties of oligomers and polymers [25-27]. The 3D real-space analysis was shown in Figure 5, and density of molecular orbital for HOMO and LUMO was shown in supporting materials Figure S1 in Supplementary Material available online at http://dx.doi.org/10.1155/2015/139382. From Figure S1, it is found that electron density distributions of the HOMO and LUMO are mainly located on the pheophytin body and there is no electron density under the polyene hydrocarbon, which are supported by charge difference density (CDD) analysis (see Figure 5). As shown, CDD shows that the excited state only occurs on the pheophytin body (where red and green represent the electron and hole, resp.). The state is an intramolecular charge transfer state (ICT) because the holes 


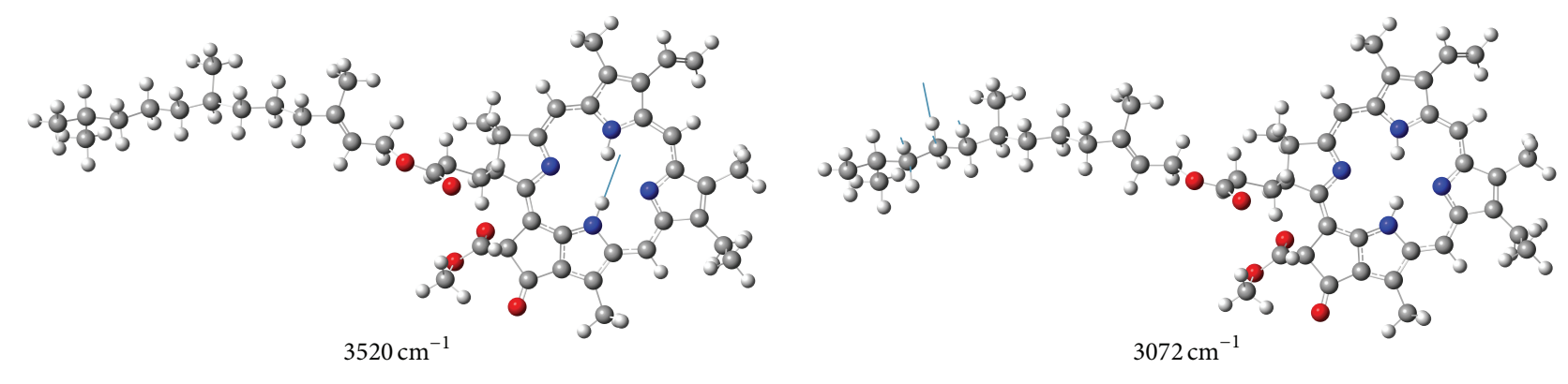

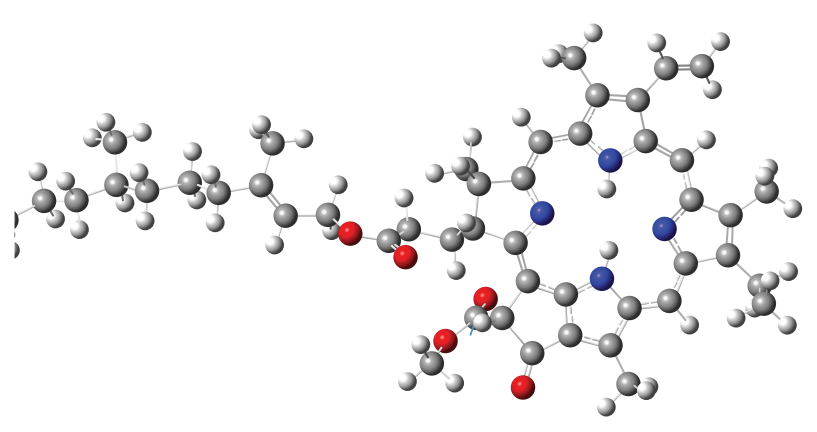

$1795 \mathrm{~cm}^{-1}$

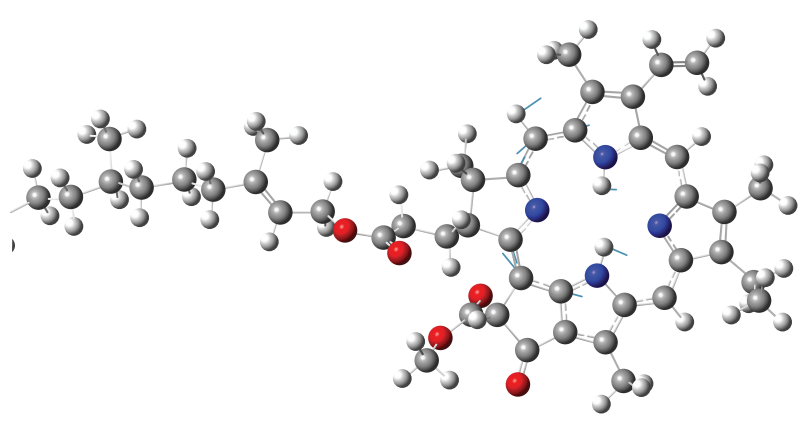

$1660 \mathrm{~cm}^{-1}$

FIGURE 3: Vibration for IR spectrum.

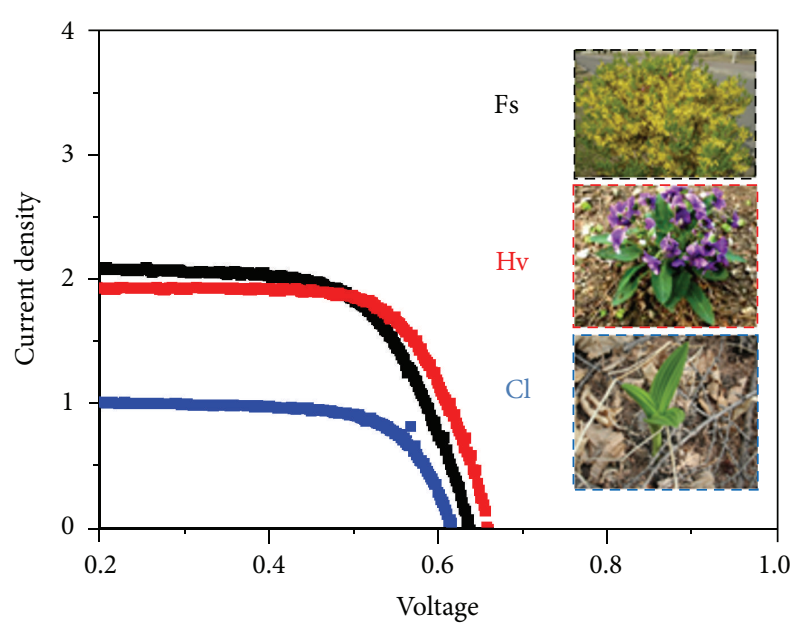

FIGURE 4: Current-voltage curve for FS (block line), Hv (red line), and $\mathrm{Cl}$ (blue line), respectively.

are located on the central rings, and electron is transferred into outside area. It is worth nothing that the red electrons are located on the attaching group $\mathrm{C}=\mathrm{O}$ of pheophytin, and the increasing electron density upon the surface of semiconductor should be an important condition for the electron injection. The density of second state is similar to the first excited state. S3 and S4 are located excited states, and there is no electron upon attaching group. At the same time, the S6 excited state is also a located excited state (which is different with S3 and S4), and Figure 5 shows that excited electron and hole pair almost only appear upon the attaching group.

For DSSCs, excited electron should be quickly injected from the discontinuous energy level of dyes into the $\mathrm{CB}$ of the semiconductor titanium dioxide. Thermodynamically, driving force of the electron injection process can be described as the difference between excited state oxidation potential $E_{\mathrm{ex}}^{\mathrm{ox}}$ and $\mathrm{CB}$ edges. From Rehm and Weller equation [30], $E_{\mathrm{ex}}^{\mathrm{ox}} \mathrm{can}$ be calculated as follows:

$$
E_{\mathrm{ex}}^{\mathrm{ox}}=E_{\mathrm{gr}}^{\mathrm{ox}}-E_{00},
$$

where $E_{\mathrm{ex}}^{\mathrm{ox}}$ and $E_{\mathrm{gr}}^{\mathrm{ox}}$ are the excited and ground state oxidation potentials and $E_{00}$ is the electronic transition energy, and the ground state oxidation potential $E_{\mathrm{gr}}^{\mathrm{ox}}$ is computed from the HOMO energy. The value of $E_{\mathrm{ex}}^{\mathrm{ox}}$ is calculated to be $-0.82 \mathrm{~V}$ which is more negative than the $\mathrm{CB}$ edge of $\mathrm{TiO}_{2}(0.5 \mathrm{~V}$ versus normal hydrogen electrode (NHE)) [31-33], and electron injection is more easy to occur owing to the bigger difference between the excited state oxidation potentials and $\mathrm{CB}$ edge.

\section{Conclusions}

Three DSSCs based on natural dyes extracted from Forsythia suspensa, Herba Violae, and Corn leaf have been studied, and optical electronic results show that the highest photoelectronic conversion efficiency $\eta=0.96 \%$ with open circuit voltage $\left(V_{\mathrm{OC}}\right)$ of $0.66 \mathrm{~V}$, short circuit current density $\left(I_{\mathrm{SC}}\right)$ of $1.97 \mathrm{~mA} \mathrm{~cm}^{-2}$, and fill factor (ff) of 0.74 . TD-DFT calculations show that the objected system has wide absorption region, and charge difference density demonstrated that there is an ICT state for the S1 state and provided the orientation 


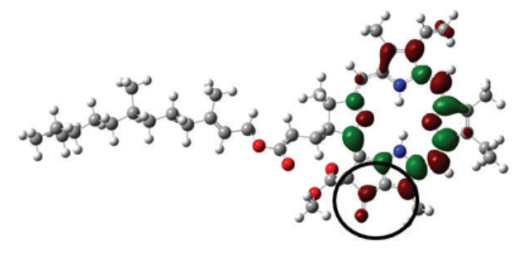

$\mathrm{S} 1$

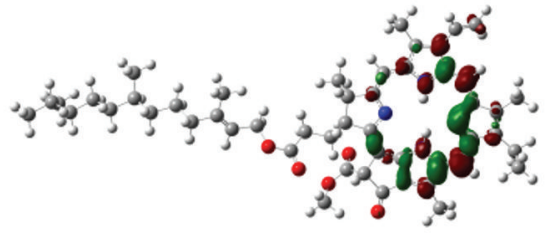

S3

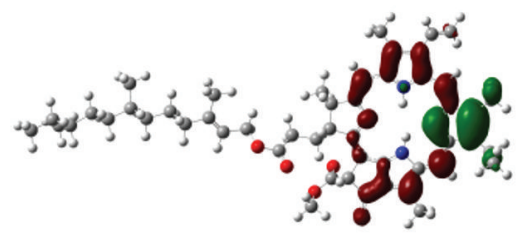

S5

FIGURE 5: Charge difference density for calculated states.

of charge transfer. Electron injection is thermodynamically permitted.

\section{Conflict of Interests}

The authors declare no conflict of interests.

\section{Acknowledgments}

This work was supported by the Fundamental Research Funds for the Central Universities (Grant no. 2572014CB31), the Heilongjiang Provincial Youth Science Foundation (Grant no. QC2013C006), and the National Natural Science Foundation of China (Grant nos. 11404055 and 11374353).

\section{References}

[1] A. Hagfeldt and M. Graetzel, "Light-induced redox reactions in nanocrystalline systems," Chemical Reviews, vol. 95, no. 1, pp. 49-68, 1995.

[2] S. Ito, S. M. Zakeeruddin, R. Humphry-Baker et al., "Highefficiency organic-dye-sensitized solar cells controlled by nanocrystalline- $\mathrm{TiO}_{2}$ electrode thickness," Advanced Materials, vol. 18, no. 9, pp. 1202-1205, 2006.

[3] N. Koumura, Z. S. Wang, S. Mori, M. Miyashita, E. Suzuki, and K. Hara, "Alkyl-functionalized organic dyes for efficient molecular photovoltaics," Journal of the American Chemical Society, vol. 128, no. 44, pp. 14256-14257, 2006.

[4] H. N. Tian, X. C. Yang, R. K. Chen et al., "Phenothiazine derivatives for efficient organic dye-sensitized solar cells," Chemical Communications, no. 36, pp. 3741-3743, 2007.

[5] K. Hara, M. Kurashige, Y. Dan-Oh et al., "Design of new coumarin dyes having thiophene moieties for highly efficient organic-dye-sensitized solar cells," New Journal of Chemistry, vol. 27, no. 5, pp. 783-785, 2003.

[6] T. Bessho, E. Yoneda, J.-H. Yum et al., "New paradigm in molecular engineering of sensitizers for solar cell applications,"
Journal of the American Chemical Society, vol. 131, no. 16, pp. 5930-5934, 2009.

[7] T. Funaki, H. Funakoshi, O. Kitao et al., "Cyclometalated ruthenium(II) complexes as near-IR sensitizers for high efficiency dye-sensitized solar cells," Angewandte Chemie, vol. 51, no. 30, pp. 7528-7531, 2012.

[8] G. Calogero, A. Bartolotta, G. Di Marco, A. Di Carlo, and F. Bonaccorso, "Vegetable-based dye-sensitized solar cells," Chemical Society Reviews, vol. 44, no. 10, pp. 3244-3294, 2015.

[9] N. A. Ludin, A. M. A.-A. Mahmoud, A. B. Mohamad, A. A. H. Kadhum, K. Sopiana, and N. S. A. Karima, "Review on the development of natural dye photosensitizer for dye-sensitized solar cells," Renewable and Sustainable Energy Reviews, vol. 31, pp. 386-396, 2014.

[10] M. Shahid, S. Ul-Islam, and F. Mohammad, "Recent advancements in natural dye applications: a review," Journal of Cleaner Production, vol. 53, pp. 310-331, 2013.

[11] M. R. Narayan, "Review: dye sensitized solar cells based on natural photosensitizers," Renewable and Sustainable Energy Reviews, vol. 16, no. 1, pp. 208-215, 2012.

[12] R. Hemmatzadeh and A. Jamali, "Enhancing the optical absorption of anthocyanins for dye-sensitized solar cells," Journal of Renewable and Sustainable Energy, vol. 7, no. 1, Article ID 013120, 2015.

[13] G. R. A. Kumara, S. Kaneko, M. Okuya, B. Onwona-Agyeman, A. Konno, and K. Tennakone, "Shiso leaf pigments for dyesensitized solid-state solar cell," Solar Energy Materials and Solar Cells, vol. 90, no. 9, pp. 1220-1226, 2006.

[14] R. Espinosa, I. Zumeta, J. L. Santana et al., "Nanocrystalline $\mathrm{TiO}_{2}$ photosensitized with natural polymers with enhanced efficiency from 400 to $600 \mathrm{~nm}$," Solar Energy Materials and Solar Cells, vol. 85, no. 3, pp. 359-369, 2005.

[15] E. Yamazaki, M. Murayama, N. Nishikawa, N. Hashimoto, M. Shoyama, and O. Kurita, "Utilization of natural carotenoids as photosensitizers for dye-sensitized solar cells," Solar Energy, vol. 81, no. 4, pp. 512-516, 2007.

[16] J. M. R. Dreizler and E. K. U. Gross, Density Functional Theory, Springer, Heidelberg, Germany, 1990. 
[17] A. D. Becke, "Density-functional exchange-energy approximation with correct asymptotic behavior," Physical Review A, vol. 38, no. 6, pp. 3098-3100, 1988.

[18] A. D. Becke, "Density-functional thermochemistry. III. The role of exact exchange," The Journal of Chemical Physics, vol. 98, no. 7, p. 5648, 1993.

[19] C. Lee, W. Yang, and R. G. Parr, "Development of the ColleSalvetti correlation-energy formula into a functional of the electron density," Physical Review B, vol. 37, no. 2, pp. 785-789, 1988.

[20] R. E. Stratmann, G. E. Scuseria, and M. J. Frisch, "An efficient implementation of time-dependent density-functional theory for the calculation of excitation energies of large molecules," The Journal of Chemical Physics, vol. 109, no. 19, pp. 8218-8224, 1998.

[21] T. Yanai, D. P. Tew, and N. C. Handy, "A new hybrid exchangecorrelation functional using the Coulomb-attenuating method (CAM-B3LYP)," Chemical Physics Letters, vol. 393, no. 1-3, pp. 51-57, 2004.

[22] M. J. Frinch, G. W. Trucks, H. B. Schlegel et al., Gaussian 09 (Revision A.1), Gaussian, Wallingford, Conn, USA, 2009.

[23] J. A. Talla, S. A. Salman, H. Sabbah, E. Yasin, and A. A. Zir, "Modeling single-walled boron nitride nanotube pressure sensor: density functional study," Nanoscience and Nanotechnology Letters, vol. 7, no. 6, pp. 500-506, 2015.

[24] G. J. Zhao and K. L. Han, "Hydrogen bonding in the electronic excited state," Accounts of Chemical Research, vol. 45, no. 3, pp. 404-413, 2012.

[25] Y. Z. Li, T. Pullerits, M. Y. Zhao, and M. T. Sun, "Theoretical characterization of the $\mathrm{PC}_{60} \mathrm{BM}$ :PDDTT model for an organic solar cell," Journal of Physical Chemistry C, vol. 115, no. 44, pp. 21865-21873, 2011.

[26] P. Song, Y. Z. Li, F. C. Ma, and M. T. Sun, "Insight into external electric field dependent photoinduced intermolecular charge transport in BHJ solar cell materials," Journal of Materials Chemistry C, vol. 3, no. 18, pp. 4810-4819, 2015.

[27] X. M. Zhao and M. D. Chen, "DFT study on the influence of electric field on surface-enhanced Raman scattering from pyridine-metal complex," Journal of Raman Spectroscopy, vol. 45, no. 1, pp. 62-67, 2014.

[28] S. M. Milenković, J. B. Zvezdanović, T. D. Andjelković, and D. Z. Marković, "The identification of chlorophyll and its derivatives in the pigment mixtures: HPLC-chromatography, visible and mass spectroscopy studies," Advanced Technologies, vol. 1, no. 1, pp. 16-24, 2012.

[29] V. Shanmugam, S. Manoharan, A. Sharafali, S. Anandan, and R. Murugan, "Green grasses as light harvesters in dye sensitized solar cells," Spectrochimica Acta-Part A: Molecular and Biomolecular Spectroscopy, vol. 135, pp. 947-952, 2015.

[30] A. Hagfeldt, G. Boschloo, L. C. Sun, L. Kloo, and H. Pettersson, "Dye-sensitized solar cells," Chemical Reviews, vol. 110, no. 11, pp. 6595-6663, 2010.

[31] D. Rehm and A. Weller, "Kinetics of fluorescence quenching by electron and H-atom transfer," Israel Journal of Chemistry, vol. 8, no. 2, pp. 259-271, 1970.

[32] C. Y. Qin and A. E. Clark, "DFT characterization of the optical and redox properties of natural pigments relevant to dyesensitized solar cells," Chemical Physics Letters, vol. 438, no. 1-3, pp. 26-30, 2007.

[33] K. Kalyanasundaram and M. Grätzel, "Applications of functionalized transition metal complexes in photonic and optoelectronic devices," Coordination Chemistry Reviews, vol. 177, no. 1, pp. 347-414, 1998. 

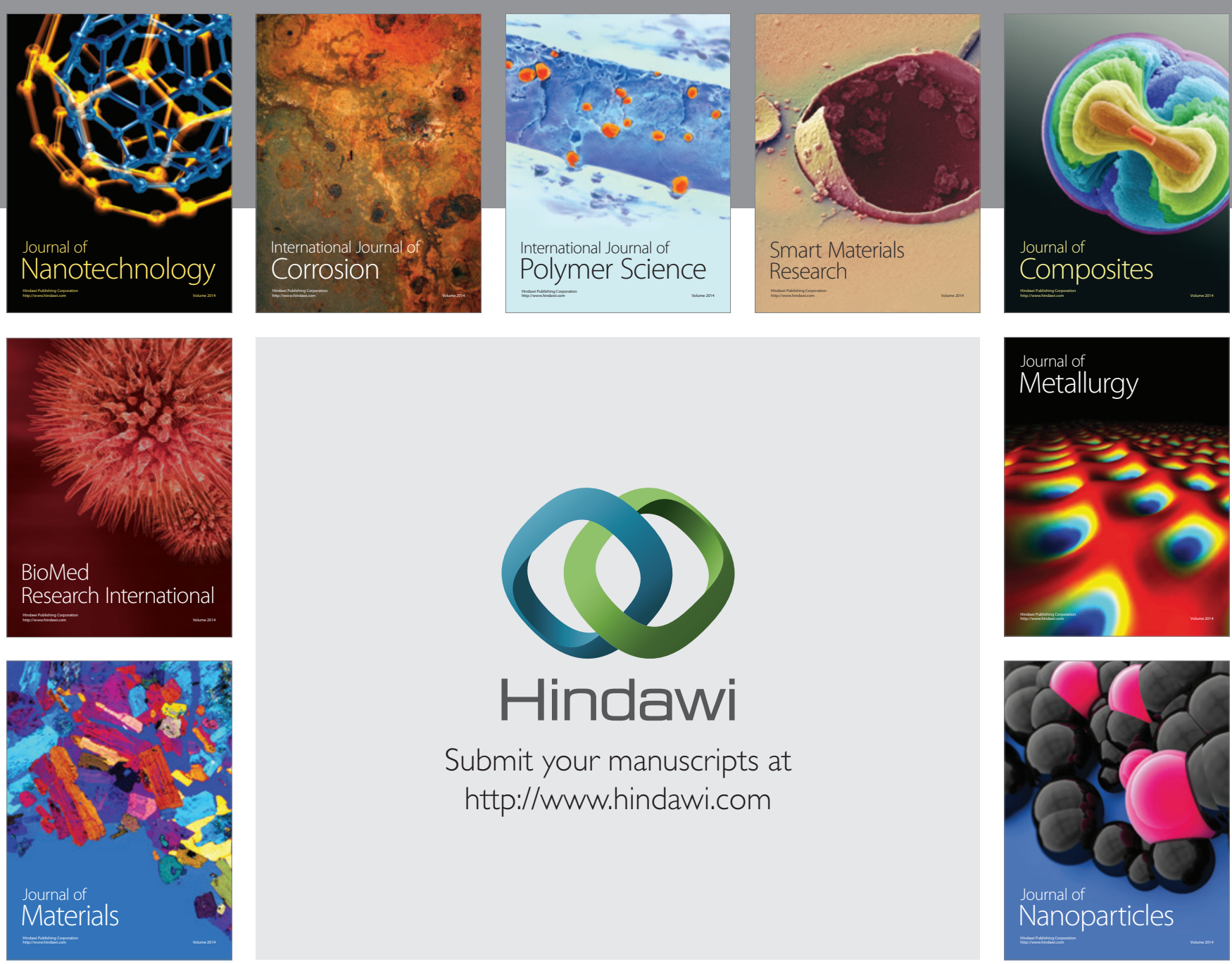

Submit your manuscripts at http://www.hindawi.com
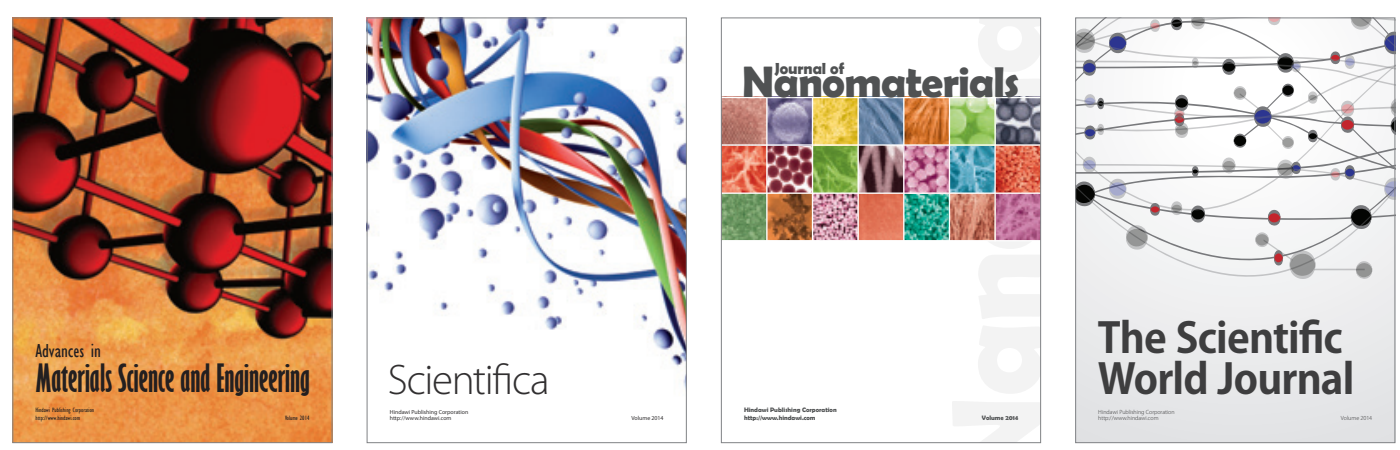

\section{The Scientific World Journal}
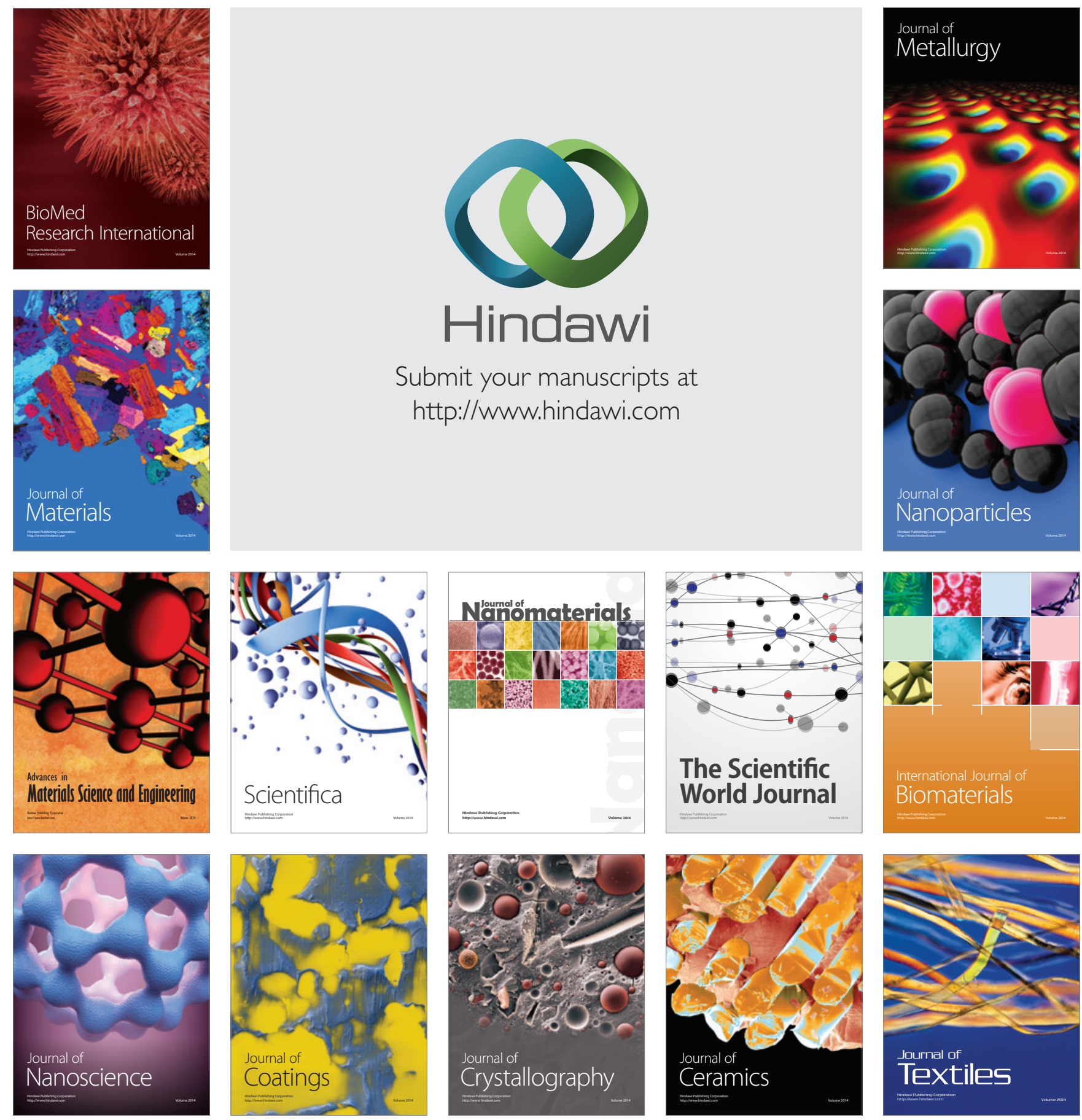